\title{
Burden of caregivers of patients with frontotemporal lobar degeneration - a scoping review
}

\author{
Tina Karnatz, ${ }^{1}$ [0 Jessica Monsees, ${ }^{1}$ Diana Wucherer, ${ }^{1}$ [0 Bernhard Michalowsky, \\ Ina Zwingmann, ${ }^{1}$ Margareta Halek, ${ }^{2,3}$ Wolfgang Hoffmann ${ }^{1,4}$ and \\ Jochen René Thyrian ${ }^{1}$ \\ ${ }^{1}$ German Center for Neurodegenerative Diseases (DZNE), Greifswald, Germany \\ ${ }^{2}$ German Center for Neurodegenerative Diseases (DZNE), Witten, Germany \\ ${ }^{3}$ Department for Nursing Science, Witten/Herdecke University, Witten, Germany \\ ${ }^{4}$ Institute for Community Medicine, University Medicine Greifswald, Greifswald, Germany
}

ABSTRACT

Background: Frontotemporal lobar degeneration (FTLD) is the second-most common cause of young-onset dementia. Personality and behavior changes lead to high caregiver stress and burden, but little support is available. Our aim is to present the evidence on the characteristics, challenges and unmet needs of caregivers as well as on possible interventions.

Methods: We conducted a scoping review on caregiver burden using PubMed, Web of Science and ScienceDirect. A total of 69 articles were considered eligible and were analyzed in the present study.

Results: Through the analysis of 69 empirical articles, our results show that caregivers of patients with FTLD are often younger in age, have children and find behavioral disturbances to be the most burdensome. Nine studies assessed the needs of and support for caregivers. Ten studies compared the burden in different forms of FTLD, 19 compared FTLD to other types of dementia, and one compared the caregiver burden between two countries. Eight studies reported on interventions for caregivers or interventions taking burden into account. One study assessed the support structure for caregivers of FTLD patients. Five case reports, eight research overviews and three reviews addressed specific needs and challenges.

Conclusions: Further research should reproduce and validate efficacious interventions and focus on underage children of FTLD patients and findings from non-Western countries. Additionally, support structures for FTLD caregivers should be assessed and extended. Awareness both in the wider population and among healthcare professionals is an urgent need for the future.

Key words: frontotemporal dementia (FTD), dementia, early onset dementia, carers, young onset dementia

\section{Introduction}

Frontotemporal lobar degeneration (FTLD) is a neurodegenerative disorder resulting from brain atrophy in the frontal and temporal lobes, leading to changes in personality, behavior, language skills and forward planning (Piguet and Hodges, 2013). A systematic review conducted in 2016 estimated that FTLD cases constitute $15 \%$ of all cases of dementia in individuals younger than 65 or 70 years (different cut-offs were used in the reviewed studies), making it

Correspondence should be addressed to: Jochen René Thyrian, German Center for Neurodegenerative Diseases (DZNE), Ellernholzstr. 1-2, 17489 Greifswald, Germany. Email: rene.thyrian@dzne.de. Received 09 Sep 2018; revision requested 10 Oct 2018; revised version received 14 Dec 2018; accepted 26 Jan 2019. First published online 15 April 2019. the second-most common form of presenile dementia after Alzheimer's Disease (AD) (Hogan et al., 2016). Factors unique to FTLD that are considered particularly burdensome for caregivers are the young age of onset, behavioral changes such as disinhibition and apathy, and an often prolonged and distressing way of obtaining a correct diagnosis. There is a lack of information as well as appropriate care facilities. Caregiver depression and reduced caregiver wellbeing can occur as a result of neglecting one's own needs (Piguet and Hodges, 2013).

Consensus criteria differentiate between behavioral variant frontotemporal dementia (bvFTD) and primary progressive aphasia (PPA) (Rascovsky et al., 2011). Primary progressive aphasia can be further divided into three subtypes: the semantic variant 
(sv-PPA, formerly semantic dementia/SD), the non-fluent/agrammatic variant (nfv-PPA, formerly progressive non-fluent aphasia/PNFA) and the logopenic variant (lv-PPA); however, lv-PPA is now widely considered to be a form of Alzheimer's disease rather than belonging to the FTLD entity (Gorno-Tempini et al., 2011). As a third variant, FTLD symptoms are known to overlap with motor neuron disease (MND, mainly amyotrophic lateral sclerosis (ALS)), corticobasal syndrome (CBS) and progressive supranuclear palsy (PSP) (Piguet and Hodges, 2013).

Patients with bvFTD typically show behavioral and personality changes, with major symptoms including apathy, disinhibition, perseveration, hoarding, mental rigidity, blunting of affect, changes in eating behavior and loss of empathy (Piguet and Hodges, 2013). Moreover, patients are notably younger at onset, being mainly $<65$ years (Hogan et al., 2016), but some patients can even be diagnosed in their early twenties (Diehl-Schmid et al., 2013).

Language skills as well as spatial cognition remain relatively preserved in bvFTD. A decline in executive functions is debatable, but its onset appears later during the course of the disease compared to AD. Approximately $10-15 \%$ of patients exhibit signs of severe amnesia and deficits in episodic memory that can be compared to those of patients with $\mathrm{AD}$, even though this is atypical for most bvFTD patients. Prevailing neuropsychological findings are changes in social cognition, e.g., the ability to empathize with others, recognize emotions and solve complex problems. Thus, the next of kin of FTLD patients describe 'coldness' and inappropriate behavior in social situations. However, physiological reactions to emotional stimuli (i.e., skin conductance) remain preserved, even though the patients perform poorly in testing. Some of those deficits may be sensitive to retraining (Piguet and Hodges, 2013).

The prevalence of FTLD cases can only be estimated within studies indicating a point prevalence between 0.01 to 4.6 per 1000 persons and an incidence of 0.0 to 0.3 per 1,000 persons per year. Accurate epidemiologic data is hard to determine since studies vary in their methodology. FTLD is associated with a relative loss of remaining life expectancy of $72 \%$ to $84 \%$, or an absolute loss of 11.5 to 15.4 years, respectively (Brodaty et al., 2012).

Currently, there are no effective pharmacological treatment options available. Drugs used for AD treatment, such as acetylcholinesterase inhibitors or NMDA receptor antagonists, as well as antipsychotic or antidepressant medications, are estimated to effectively alleviate behavioral symptoms. Aside from pharmacological options, no evidence-based interventions for patients with FTLD exist, and the burden among those caring for FTLD patients is high (Piguet and Hodges, 2013).

The last comprehensive review examining burden in caregivers of patients with FTLD was conducted by Nunnemann et al. (2012) with a similar systematic search strategy (search keywords: "frontotemporal or FT(L)D" and "caregiver or carer"), making no restrictions regarding study design but including non-medical databases (Medline, Cinahl, Embase, Cochrane Library: Cochrane Dementia and Cognitive Improvement Group, Psyndex, PsycINFO, SocINDEX, SOWIPORT, WISO, Social Sciences Citation Index, Periodicals Index Online). At the time their review was conducted, no randomized controlled interventions could be identified for caregiver burden in FTLD, and only one study focused on caregiver needs (Nicolaou et al., 2010). The amount of literature on caregiver burden in FTLD has risen so that new implications for caregiving, especially in the form of interventions, were added, which makes another comprehensive scoping review on the topic reasonable. Thus, the aim of this review is to give an overview on existing literature about factors contributing to caregivers' distress and on interventions that have the potential to decrease the burden of the caregivers of people with FTLD.

\section{Methods}

For the presentation and synthesis of existing knowledge about burden of caregivers of persons with FTLD, we chose the format of a scoping review (Peters et al., 2017; Tricco et al., 2016). The aim of this type of review is to search all existing literature concerning a research question, to summarize it and to map the current knowledge. In consequence, research gaps and implications for future studies can be obtained. In contrast to a systematic review, no quality assessment or meta-analyses are performed (Tricco et al., 2016).

A systematic literature search was conducted in April 2017. The databases PubMed, Web of Science and ScienceDirect were searched for the terms "FTD", "FTLD", "ALS" or "aphasia" and "caregiver burden", respectively. We therefore extended the search terms to cover appropriate research in the overlap between the fields of ALS-FTD and aphasia. No limitations were made regarding the type of study, including posters and congress publications, and publication date; articles were excluded if they were in a language other than English or German. All studies that focused on caregivers that included an FTLD cohort as well as interventions that 


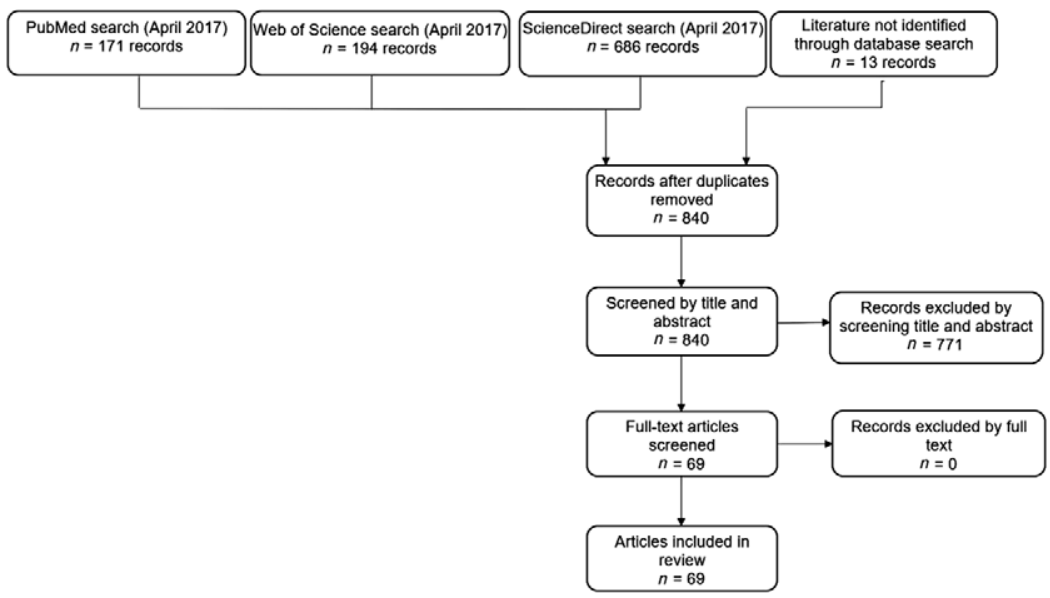

Figure 1. Literature search flow chart.

assessed caregiver burden in the said cohort were included. When we searched the ScienceDirect database, the following filters were applied: for "ALS caregiver burden" and "aphasia caregiver burden", the topic "dementia" was set to exclude a large number of articles addressing other aspects of these diseases.

Search results were screened for eligibility in a twostep process, excluding articles by title and by abstract. The flow chart is illustrated in Figure 1. Fifty-six fulltext articles were identified. Another 13 applicable articles that could be identified from references - but had not appeared as results in the database search were added to the list of literature sources to be reviewed, yielding a total of 69 publications. Ambiguities concerning the inclusion of articles were resolved by consensus.

Following the inclusion of articles, a table was developed for summarizing articles. An example can be found in Table 1, the comprehensive summary of all articles is available as supplementary material published online attached to the electronic version of this paper. The country of origin was assessed to determine any bias that may be associated with certain countries or regions contributing the majority of research findings and identify the need for crosscultural validation of results. The characteristics of participants are given, as are the methods and measures used. In interventional studies, the intervention procedure is presented separately. The main findings are outlined with a focus on results concerning FTLD patients and their caregivers in studies that also include other types of dementia. Self-reported biases are included in the summary, but no systematic quality assessment was performed due to the nature of a scoping review. In the analysis, findings were grouped based on the methods of the studies; the socioeconomic and demographic characteristics of the study populations; the needs, problems and challenges for caregivers; and interventions. Findings from quantitative and qualitative studies alike are presented together within these categories to outline key findings of the research.

\section{Results}

\section{Design and methods of the included studies}

Of the 69 papers included in this review, 42 were published between 2012 and 2017, underpinning the implication for a comprehensive review. Fortyfour out of 69 articles are quantitative studies of an observational, descriptive nature. Their results will be summarized in order to give an overview about the prevalence of caregiver burden, its causes and influencing variables. Among those studies are three poster presentations from the Alzheimer's Association International Conference on Alzheimer's Disease 2010 (Merrilees et al., 2010), the Alzheimer's Association International Conference 2012 (Ng et al. 2012) and the 2015 American Association for Geriatric Psychiatry (AAGP) Annual Meeting (Uflacker et al., 2015).

Eight publications are intervention studies for caregivers or for FTLD patients with consideration of caregiver burden and are presented in Table 2. Another eight papers were research overviews, summarizing knowledge about caregiver-related topics; additionally, three systematic or integrative reviews were found. Properties of reviews and research articles can be found in Table 3. The remaining articles consist of five case reports (for a detailed description, see Table 4) and one study reporting on structural support provision for caregivers of persons with FTLD (Ibach et al., 2004). 
Table 1. Exemplary summary table

Reference

Type

Location/country

Aim/subject

Participants (number, patient diagnosis, gender, age range, race, ethnicity, type of residency [home, care facility], initial treatment, caregiver relationship to patient, initial scores)

Methods/measures

Interventions (where applicable)

Outcomes (variables, main findings)

Limitations
Armstrong, Nicole; Schupf, Nicole; Grafman, Jordan; Huey, Edward D. (2013): Caregiver burden in frontotemporal degeneration and corticobasal syndrome. In Dementia and geriatric cognitive disorders 36 (5-6), pp. 310-318. DOI: 10.1159/000351670.

Controlled cohort study, descriptive study

USA

To assess the association between behavioral symptoms and caregiver burden in patients with frontotemporal dementia (FTD) and corticobasal syndrome (CBS)

267 caregivers of FTD/CBS patients in total who received questionnaires ( $n=180$ FTD caregivers, $n=87$ CBS caregivers)

FTD/CBS diagnosis confirmed at National Institutes of Health according to published consensus criteria

102 caregivers completed FrSBe and ZBI $(n=61$ FTD caregivers, $n=41$ CBS caregivers)

Age of patient: FTD $60 \pm 9$ years; CBS: $66 \pm 8$ years; total: $63 \pm 9$ years

Gender of patient: FTD 30 male/31 female; CBS 21 male/20 female; (total 51 male/51 female)

Race of patient: FTD, 60 white/Caucasian, 1 other; CBS, 37

white/Caucasian, 2 African American, 2 Asian/Pacific

Islanders

Caregiver relationship to patient: FTD 53 significant other, 8 family members; CBS 34 significant other, 5 family members, 1 friend, 1 paid caregiver

FrSBe - T-score used as main predictor variable, representing frontal lobe dysfunction ( $\geq$ cutoff score 65 ), adjusted for gender, level of education and age

ZBI - total score used as main outcome variable, representing caregiver burden ( $>$ cutoff score 24 )

Multivariate regression model using T-score, ZBI score, relationship to patient and diagnosis

T-scores from apathy and disinhibition subscales of the FrSBe examined separately as independent predictors

Associations between groups of (1) caregivers of patients with apathy and disinhibition, (2) caregivers of patients with only apathy, (3) caregivers of patients with only disinhibition and (4) caregivers of patients without either apathy or disinhibition, examined by one-sample t-test

Associations regarding type of diagnosis examined by between-group twosample t-test

Relationship to patient and type of diagnosis considered to be potential confounders

None

Caregiver burden $=$ ZBI scores

Frontal lobe dysfunction $=$ FrSBe $T$-scores

Caregivers of patients with frontal lobe dysfunction had 13.0 times the odds of experiencing caregiver burden than caregivers of patients without frontal lobe dysfunction

Association between the apathy and disinhibition subscales of the FrSBe and caregiver burden -57 patients exhibited both apathy and disinhibition

Executive dysfunction subscale of the FrSBe not considered a covariate since sample was homogenous in attaining scores $\geq 65$

Apathy and disinhibition can co-occur; apathy can occur without disinhibition, whereas disinhibition without apathy is very rare

FTD subtypes were not considered separately due to small patient numbers

FrSBe narrow in scope - some symptoms that are included in the NPI are not measured

No information available about dementia severity in patients

No information about caregiver characteristics (e.g., age, gender) available No control/comparison group 
Table 2. Interventions

\begin{tabular}{|c|c|c|c|c|}
\hline REFERENCE & AIM & PROCEDURE & PARTICIPANTS & RESULTS \\
\hline \multicolumn{5}{|c|}{ Pharmacological interventions } \\
\hline Boxer et al. (2013) & $\begin{array}{l}\text { Effect of memantine } \\
\text { (NMDA receptor } \\
\text { antagonist) in FTD }\end{array}$ & $\begin{array}{l}\text { RCT with intention-to-treat analysis; } \\
\text { behavior, cognition, and caregiver } \\
\text { burden among other outcomes }\end{array}$ & $\begin{array}{l}\text { IG: } 31 \text { bvFTD, } 8 \text { SD } \\
\text { CG: } 33 \text { bvFTD, } 9 \text { SD }\end{array}$ & $\begin{array}{l}\text { No difference in caregiver burden and } \\
\text { cognition; only transient improvement } \\
\text { in behavior }\end{array}$ \\
\hline Vercelletto et al. (2011) & $\begin{array}{l}\text { Effect of memantine } \\
\text { (NMDA receptor } \\
\text { antagonist) in bvFTD }\end{array}$ & $\begin{array}{l}\text { RCT with intention-to-treat analysis; } \\
\text { behavior, cognition, and caregiver } \\
\text { burden among other outcomes }\end{array}$ & $\begin{array}{l}\text { IG: } 23 \text { bvFTD } \\
\text { CG: } 26 \text { bvFTD }\end{array}$ & $\begin{array}{l}\text { No differences in caregiver burden and } \\
\text { cognition; slightly quicker increase in } \\
\text { behavioral disturbances in CG }\end{array}$ \\
\hline Moretti et al. (2004) & $\begin{array}{l}\text { Effect of rivastigmine } \\
\text { (acetylcholinesterase and } \\
\text { butyrylcholinesterase } \\
\text { inhibitor) in FTD }\end{array}$ & $\begin{array}{l}\text { Intervention (not blinded, not } \\
\text { randomized); behavior, cognition, } \\
\text { caregiver stress among other } \\
\text { outcomes }\end{array}$ & $\begin{array}{l}\text { IG: } 20 \text { FTD } \\
\text { CG: } 20 \text { FTD }\end{array}$ & $\begin{array}{l}\text { Behavioral disturbances decreased in IG } \\
\text { and increased in CG; no changes in } \\
\text { cognition; caregiver stress decreased in } \\
\text { IG compared to CG }\end{array}$ \\
\hline \multicolumn{5}{|l|}{ Caregiver interventions } \\
\hline Diehl et al. (2003) & $\begin{array}{l}\text { Effect of a caregiver support } \\
\text { group }\end{array}$ & $\begin{array}{l}7 \text { structured sessions moderated by } \\
\text { an expert providing FTD-specific } \\
\text { information (legal, social, coping); } \\
\text { unmoderated sessions followed; } \\
\text { evaluation }\end{array}$ & $\begin{array}{l}8 \text { caregivers of patients with } \\
\text { FTD, SD and frontal } \\
\text { Binswanger's disease }\end{array}$ & $\begin{array}{l}\text { Intervention was rated as helpful; } \\
\text { knowledge increased and mutual support } \\
\text { was sought; new contacts were developed }\end{array}$ \\
\hline O’Connell et al. (2014) & $\begin{array}{l}\text { Effect of a video-conference } \\
\text { telehealth support group in } \\
\text { Saskatchewan }\end{array}$ & $\begin{array}{l}\text { Monthly moderated open-agenda } \\
\text { sessions attended in a telehealth } \\
\text { center nearest to the participant; } \\
\text { one in-person workshop; } \\
\text { evaluation }\end{array}$ & $\begin{array}{l}11 \text { spouses of patients with } \\
\text { PNFA, SD, bvFTD, } \\
\text { secondary dementia, } \\
\text { or frontal strokes }\end{array}$ & $\begin{array}{l}\text { Intervention was rated as helpful due to } \\
\text { exclusivity to spouses and FTD patients } \\
\text { in openly discussing specific problems; } \\
\text { technical difficulties and long travel to } \\
\text { telehealth sites were problematic. }\end{array}$ \\
\hline Dowling et al. (2014) & $\begin{array}{l}\text { Effect of the Life Enhancing } \\
\text { Activities for Family } \\
\text { Caregivers Intervention } \\
\text { (LEAF) in FTD caregivers }\end{array}$ & $\begin{array}{l}\text { RCT; IG completed } 5 \text { skill-building } \\
\text { sessions for positive affect and } \\
\text { coping; affect, mood, stress, } \\
\text { distress and burden measured }\end{array}$ & $\begin{array}{l}\text { IG: } 12 \text { caregivers } \\
\text { CG: } 12 \text { caregivers } \\
\text { (sessions without } \\
\text { skill-building }\end{array}$ & $\begin{array}{l}\text { Positive affect increased, negative affect and } \\
\text { stress decreased, and caregiver burden } \\
\text { significantly improved in the IG } \\
\text { compared to the CG. The risk for } \\
\text { depression decreased in the IG, and the } \\
\text { intervention was highly recommended. }\end{array}$ \\
\hline Mioshi et al. (2013b) & $\begin{array}{l}\text { Effect of an intervention for } \\
\text { improving cognitive } \\
\text { reappraisal and coping skills } \\
\text { in FTD caregivers }\end{array}$ & $\begin{array}{l}\text { Not randomized; IG completed } 15 \\
\text { group sessions for training } \\
\text { (e.g., problem solving, } \\
\text { reframing); psychological } \\
\text { assessment }\end{array}$ & $\begin{array}{l}\text { IG: } 9 \text { caregivers } \\
\text { CG: } 12 \text { caregivers }\end{array}$ & $\begin{array}{l}\text { Caregiver burden and reaction to } \\
\text { disruptive behavior improved in IG and } \\
\text { remained unchanged in CG. }\end{array}$ \\
\hline \multirow{2}{*}{$\begin{array}{l}\text { Patient intervention } \\
\text { O'Connor et al. (2016) }\end{array}$} & & & & \\
\hline & $\begin{array}{l}\text { Effect of the Tailored Activities } \\
\text { Program (TAP) for patients } \\
\text { on caregiver situation }\end{array}$ & $\begin{array}{l}\text { Activities tailored to the two patients' } \\
\text { abilities implemented; assessment } \\
\text { of patient behavior, cognition, } \\
\text { caregiver confidence and time } \\
\text { spent caring }\end{array}$ & $\begin{array}{l}\text { Case 1: 51-year-old woman } \\
\text { with bvFTD, husband and } \\
\text { two children; } \\
\text { Case 2: } 62 \text {-year-old man with } \\
\text { svPPA and daughter }\end{array}$ & $\begin{array}{l}\text { Case 1: Patient ADLs and behavior } \\
\text { improved, cognition declined, less time } \\
\text { spent caring, more confidence } \\
\text { Case 2: Vigilance times but also confidence } \\
\text { decreased, some symptoms produced } \\
\text { less distress. }\end{array}$ \\
\hline
\end{tabular}


Table 3. Reviews and research overviews

\begin{tabular}{|c|c|c|c|}
\hline REFERENCE & TOPIC/TYPE & FINDINGS & $\begin{array}{l}\text { IMPLICATIONS FOR } \\
\text { CAREGIVING }\end{array}$ \\
\hline \multicolumn{4}{|l|}{ Reviews } \\
\hline $\begin{array}{l}\text { Caceres } \\
\text { et al. (2016) }\end{array}$ & $\begin{array}{l}\text { Integrative review: Burden and } \\
\text { problems of family caregivers } \\
\text { in FTD (non-primary settings } \\
\text { and studies including other } \\
\text { non-FTD dementias excluded) }\end{array}$ & $\begin{array}{l}8 \text { quantitative } / 3 \text { qualitative } \\
\text { articles, assessed using } \\
\text { the Crowe Critical } \\
\text { Appraisal Tool. }\end{array}$ & See text \\
\hline $\begin{array}{l}\text { Nunnemann } \\
\text { et al. }(2012)\end{array}$ & $\begin{array}{l}\text { Systematic review: caregiver } \\
\text { burden in FTLD }\end{array}$ & $\begin{array}{l}10 \text { publications focusing on } \\
\text { burden/16 publications } \\
\text { focusing on problems; no } \\
\text { RCTs could be identified; } \\
\text { eight interventions. }\end{array}$ & \\
\hline $\begin{array}{l}\text { Shinagawa } \\
\text { et al. }(2015)\end{array}$ & $\begin{array}{l}\text { Systematic review: } \\
\text { non-pharmacological } \\
\text { management of } \\
\text { behavioral symptoms } \\
\text { in FTD; exclusion of } \\
\text { publications focusing on, } \\
\text { e.g., language impairments } \\
\text { and articles focusing on } \\
\text { ALS/MND management }\end{array}$ & $\begin{array}{l}4 \text { clinical trials } / 5 \text { case reports; } \\
\text { higher evidence for } \\
\text { interventions aimed at } \\
\text { caregivers than for patient } \\
\text { interventions/environmental } \\
\text { strategies. }\end{array}$ & \\
\hline \multicolumn{4}{|l|}{$\begin{array}{l}\text { Educational } \\
\quad \text { articles }\end{array}$} \\
\hline $\begin{array}{l}\text { Houseman } \\
\quad \text { et al. (2013) }\end{array}$ & $\begin{array}{l}\text { Practical suggestions for } \\
\text { nurses caring for a patient } \\
\text { with FTD }\end{array}$ & $\begin{array}{l}\text { Main problems occur with } \\
\text { cognitive impairment and } \\
\text { behavioral disturbances, } \\
\text { e.g., impaired interactions } \\
\text { with others. }\end{array}$ & $\begin{array}{l}\text { Nurses should provide education } \\
\text { about the disease and clarify the } \\
\text { difference between FTD and } \\
\text { AD; they should address safety } \\
\text { and environmental issues such } \\
\text { as medication management, } \\
\text { driving, financial resources and } \\
\text { the use of potentially dangerous } \\
\text { objects and tools. }\end{array}$ \\
\hline $\begin{array}{l}\text { Massimo } \\
\quad \text { et al. (2014) }\end{array}$ & Apathy in FTD & $\begin{array}{l}\text { Lack of goal-directed behavior; } \\
\text { the initiation, planning or } \\
\text { motivation for an action } \\
\text { can be impaired. }\end{array}$ & $\begin{array}{l}\text { Often overlooked in care because } \\
\text { it usually does not cause } \\
\text { distress; determining the } \\
\text { subtype of apathy can help } \\
\text { provide specific interventions, } \\
\text { e.g., rewards for motivational } \\
\text { problems or restructuring } \\
\text { complex activities for patients } \\
\text { with planning difficulties. }\end{array}$ \\
\hline $\begin{array}{l}\text { McCarter } \\
\quad \text { et al. }(2016)\end{array}$ & Sleep disturbances in FTD & $\begin{array}{l}\text { The most common sleep } \\
\text { disturbances observed are } \\
\text { sleep disordered breathing, } \\
\text { i.e., apnea, insomnia and } \\
\text { excessive daytime sleepiness; } \\
\text { REM sleep behavior } \\
\text { disorder has been observed. }\end{array}$ & $\begin{array}{l}\text { No guidelines for the treatment of } \\
\text { sleep disturbances were } \\
\text { available at that time; sleep } \\
\text { disturbances were found to } \\
\text { greatly contribute to caregiver } \\
\text { burden. }\end{array}$ \\
\hline
\end{tabular}


Table 3. Continued

\begin{tabular}{|c|c|c|c|}
\hline REFERENCE & TOPIC/TYPE & FINDINGS & $\begin{array}{c}\text { IMPLICATIONS FOR } \\
\text { CAREGIVING }\end{array}$ \\
\hline Merrilees (2007) & $\begin{array}{l}\text { A model to manage } \\
\text { behavioral disturbances } \\
\text { in FTD }\end{array}$ & $\begin{array}{l}\text { Understanding the underlying } \\
\text { pathology as a cause for } \\
\text { erratic behavior is crucial to } \\
\text { enable modification. }\end{array}$ & $\begin{array}{l}\text { The antecedent-behavior- } \\
\text { consequence (ABC) model is } \\
\text { presented to approach and } \\
\text { react to such behaviors. For } \\
\text { instance, frontal lobe atrophy } \\
\text { (A) causes disinhibition in the } \\
\text { patient, which makes others feel } \\
\text { uncomfortable (B). Caregivers } \\
\text { could react by explaining the } \\
\text { behavior using a business card } \\
\text { format and limiting contact } \\
\text { with others (C). Behaviors } \\
\text { could also be modified by a } \\
\text { substitution of potentially } \\
\text { dangerous or disruptive } \\
\text { behaviors. Causes other than } \\
\text { frontotemporal degeneration, } \\
\text { e.g., infections as a cause for } \\
\text { changes in toilet habits, must be } \\
\text { ruled out first. }\end{array}$ \\
\hline $\begin{array}{l}\text { O'Connor } \\
\quad \text { et al. }(2014)\end{array}$ & $\begin{array}{l}\text { Functional disabilities } \\
\text { in different subtypes } \\
\text { of aphasia }\end{array}$ & $\begin{array}{l}\text { Caregivers of svPPA patients } \\
\text { report lower burden levels } \\
\text { than those of bvFTD } \\
\text { patients; impairments in } \\
\text { ADLs can occur as a result } \\
\text { of patients' strict routines } \\
\text { and inability to understand } \\
\text { complex instructions. }\end{array}$ & $\begin{array}{l}\text { Professionals are advised to } \\
\text { educate caregivers about the } \\
\text { disease and to enable them to } \\
\text { accept and adapt to constant } \\
\text { changes; specific } \\
\text { recommendations for } \\
\text { modifying the patient's } \\
\text { environment and management } \\
\text { of everyday life are provided. } \\
\text { For example, using images } \\
\text { instead of written instructions } \\
\text { and using familiar products can } \\
\text { enable the patient to carry out } \\
\text { tasks independently. }\end{array}$ \\
\hline
\end{tabular}

\section{Outcomes and measures of quantitative studies}

The most frequently used measures to assess caregiver burden and distress in the 44 quantitative articles were the Zarit Burden Interview (ZBI, $n=10)$, the short ZBI $(n=11)$ and the Neuropsychiatric Inventory (NPI, $n=9$ ). Other assessments used were the Caregiver Burden Scale (CBS, $n=2)$, the Caregiver Burden Index (CBI, $n=3)$, the Caregiver Strain Index (CSI, $n=3$ ), the Screen for Caregiver Burden (SCB, $n=1$ ) and a Visual Analogue Scale $(n=4)$. References to the respective studies can be found in Table 5 . The studies used different cut-offs to determine and categorize caregiver burden and distress. Cut-off values as well as other assessments (e.g., depression, social network, stress) are stated in the summary of each article (see supplementary material) where applicable.

\section{Sample characteristics of the studies}

A total of $n=3355$ patients and $n=3365$ caregivers were included in the quantitative studies, with at least 1453 thereof suffering from some kind of frontotemporal lobar degeneration. Of the $n=44$ quantitative studies, all but ten studies relied on diagnoses according to consensus criteria or diagnoses confirmed by a specialized healthcare professional, the others did not report how the diagnoses were obtained (Brioschi Guevara et al., 2015; Bristow et al., 2008; Chow et al., 2011; Cosseddu et al., 2013; Denny et al., 2012; Merrilees et al., 2010; Ng et al., 2012; Uflacker et al., 2015; Wong and Wallhagen, 2012, 2014). All participants in case studies were diagnosed according to consensus criteria, as well as participants in four intervention studies; the other four, however, relied on self-report or did not state the source of diagnosis (Dowling et al., 2014; 


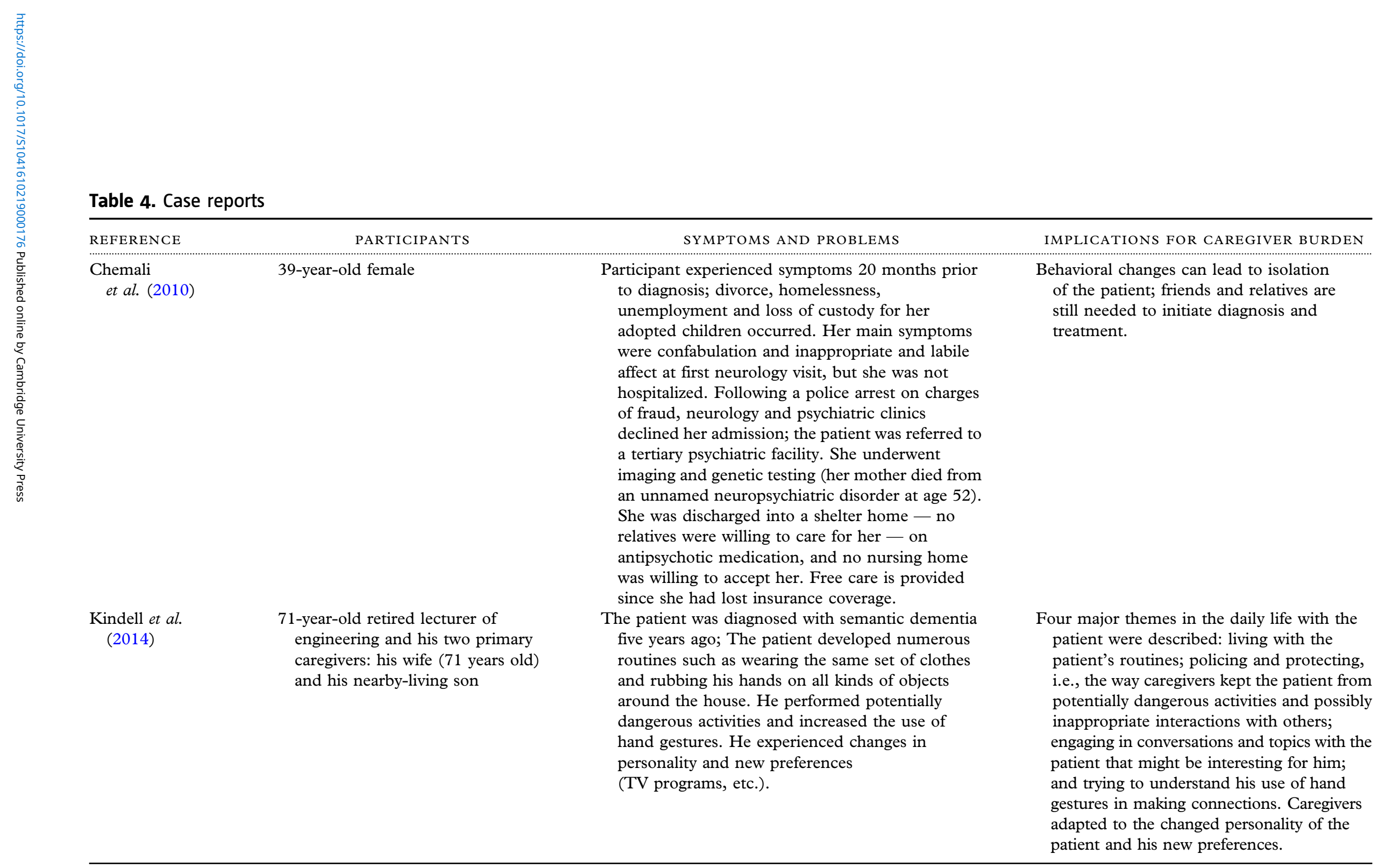

unemployment and loss of custody for her

were confabulation and inappropriate and labile

affect at first neurology visit, but she was not

ission; the patient was referred to The patient was diagnosed with semantic dementi years ago; The patient developed numerous routines such as wearing the same set of clothes dangerous activities and increased the use of patient and his new preferences. 


\section{Table 4. Continued}

\begin{tabular}{|c|c|c|c|}
\hline REFERENCE & PARTICIPANTS & SYMPTOMS AND PROBLEMS & IMPLICATIONS FOR CAREGIVER BURDEN \\
\hline $\begin{array}{l}\text { Kumamoto } \\
\text { et al. (2004) }\end{array}$ & $\begin{array}{l}\text { Case 1: } 69 \text {-year-old patient and her } \\
77 \text {-year-old husband caregiver. } \\
\text { Case 2: } 69 \text {-year-old male with his } \\
\text { 62-year-old wife and one son living } \\
\text { nearby. }\end{array}$ & $\begin{array}{l}\text { Case 1: She had symptoms for } 15 \text { years and attended } \\
\text { day care for four years. She lost her job as a shop } \\
\text { assistant due to her symptoms. } \\
\text { Case } 2 \text { : He developed symptoms at age } 63 \text { and was } \\
\text { diagnosed four years later. } \\
\text { Both patients were driving dangerously and, after } \\
\text { their licenses were revoked, were walking around } \\
\text { restlessly around the house and the neighborhood. } \\
\text { Both patients were forcing large amounts of food } \\
\text { into their mouths without proper chewing and } \\
\text { swallowing. Inappropriate and stereotypic } \\
\text { behavior led to refusal of admission by hospitals } \\
\text { and other institutions. Patients were reported to be } \\
\text { able, to some extent, to understand what was being } \\
\text { said to them and to perform certain activities, e.g., } \\
\text { slicing vegetables. }\end{array}$ & $\begin{array}{l}\text { Patients require constant vigilance; } \\
\text { grooming and bathing were entirely carried } \\
\text { out by caregivers and complicated by } \\
\text { patients' unpredictable behavior. Urinary } \\
\text { and fecal incontinence required a large } \\
\text { amount of cleaning; eating behavior caused } \\
\text { the need for feeding and resulted in dental } \\
\text { problems. }\end{array}$ \\
\hline $\begin{array}{l}\text { Massimo } \\
\text { et al. (2013) }\end{array}$ & $\begin{array}{l}\text { Two wives in their mid-fifties to early } \\
\text { sixties caring for their husbands } \\
\text { (diagnosed with FTD for }<2 \\
\text { years). }\end{array}$ & $\begin{array}{l}\text { Emotionally cold patients, described as } \\
\text { 'inconsiderate', lacked insight about the disease. } \\
\text { They experienced personality changes, loss of } \\
\text { memory, and reduced functioning in everyday life. }\end{array}$ & $\begin{array}{l}\text { Five recurring themes are described: } \\
\text { Identity and role change - the wives needed } \\
\text { to adapt to their new roles as caregivers } \\
\text { while the marital relationship was gradually } \\
\text { lost; isolation - both caregivers were unable } \\
\text { to speak to the patient about the situation } \\
\text { since they were lacking insight; anger - } \\
\text { caused by erratic behavior, emotional } \\
\text { coldness and lack of reciprocated feelings by } \\
\text { the patient; facing the future and building } \\
\text { ideas for a good day; and reframing - the } \\
\text { separation of the disease from the patient } \\
\text { and reminding themselves of the pathology } \\
\text { that causes the symptoms. }\end{array}$ \\
\hline
\end{tabular}




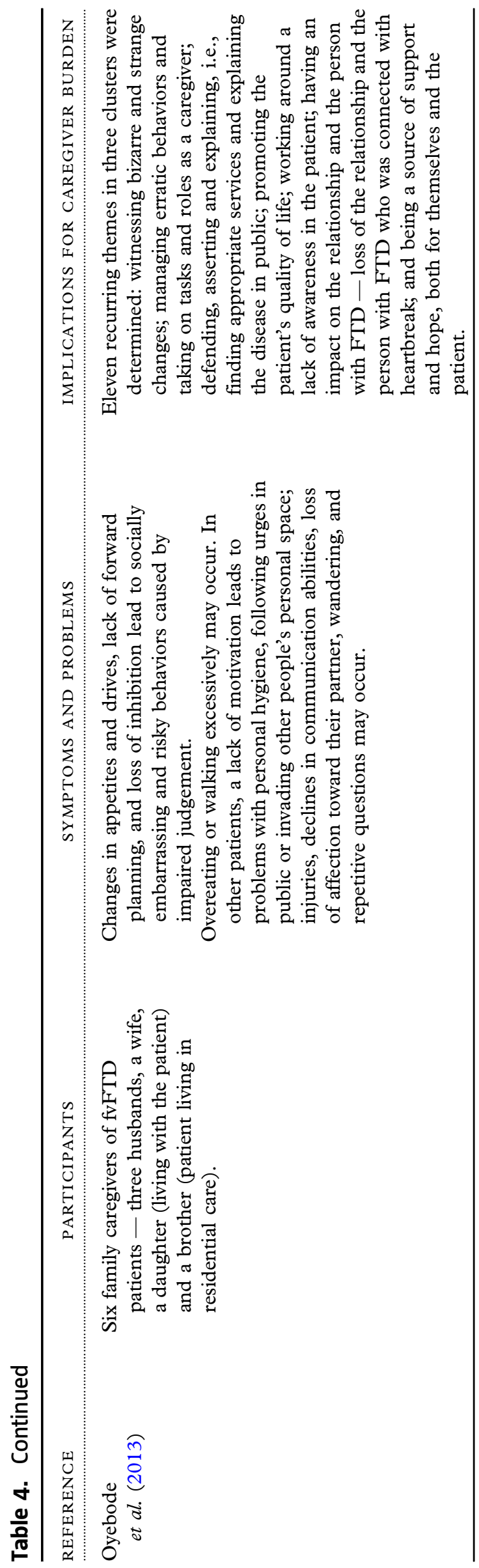

Mioshi et al., 2013b; O'Connell et al., 2014; O'Connor et al., 2016). Eighteen studies did not further specify the FTLD diagnosis. Diagnoses of patients suffering from an illness belonging to the entity of FTLD included behavioral and frontal variant FTLD (16 studies), semantic dementia (10 studies), non-fluent aphasia (6 studies) or a type of aphasia not specified (4 studies). References about the studies reporting diagnoses can be found in Table 5. It should be noted that the literature is inconsistent in terminology, with older publications using the abbreviations SD and PNFA rather than the nomenclature suggested by Gorno-Tempini et al. (2011). Overlapping syndromes were found in 17 studies: corticobasal syndrome (4 studies) and progressive supranuclear palsy (2 studies), these studies can be found in Table 5 .

The largest group of overlapping types of FTLD are patients with MND, mostly ALS (six studies, see Table 5). Referring to measurements, five of the six studies examining ALS-FTD (all except Lillo et al., 2012) stated that the El Escorial criteria were used for determining the ALS diagnosis. It should be noted that the online survey by Chow et al. (2011) allowed participants to report more than one diagnosis. The studies of Mourik et al. (2004) and Riedijk et al. (2006, 2008, 2009) used data from the same cohort, as did Diehl-Schmid et al. (2013) and Roche et al. (2015), as well as Wong and Wallhagen (2012, 2014), respectively.

\section{Country/region of origin}

The vast majority of the observed population are cohorts from Europe (22 studies), the US/ Canada (24 studies) and Australia (16 studies), see Table 5 for references. The only study to compare caregiver burden between two countries - India and Australia- was conducted by Mekala et al. (2013). Indian caregivers were found to provide a significantly higher number of hours of care to more severely impaired patients. This arrangement did not result in a higher burden than in Australian caregivers, but in significantly higher levels of anxiety, implying that caregiving might affect people from different cultures in different aspects of life. Mekala et al. (2013) argued that the higher level of anxiety in India might on the one hand be caused by the cultural variation of emotional expression, with symptoms like anxiety prevailing in Asian and Indian cultures over depressive symptoms. Moreover, a lack of supportive healthcare, home-based care and the symptoms regarded as being "normal" in the ageing process contribute to anxiety because problems and concerns cannot be adequately addressed. 
Table 5. Study characteristics

NUMBER OF
STUDIES RHARACTERISTIC $\quad$ REFERENCES

Measures to assess caregiver burden in quantitative studies

Zarit Burden Interview

10

Short Zarit Burden Interview

11

Neuropsychiatric Inventory

Caregiver Burden Scale

Caregiver Burden Index

Caregiver Strain Index

Screen for Caregiver Burden

Visual Analogue Scale

FTLD diagnoses in quantitative studies Not specified

bvFTD/fvFTD

Aphasia not specified

PNFA

Overlap syndromes in quantitative studies

CBS

PSP

MND
Andrews et al. (2017), Armstrong et al. (2013), BoutoleauBretonniere et al. (2008), Brodaty et al. (2014), Davis and Tremont (2007), Kaiser and Panegyres (2006), Knutson et al. (2008), Liu et al. (2017), Nicolaou et al. (2010), Uflacker et al. (2015)

Hsieh et al. (2013), Hsieh et al. (2016), Kaizik et al. (2017), Kumfor et al. (2014), Kumfor et al. (2016), Lillo et al. (2012), Lima-Silva et al. (2015), Mekala et al. (2013), Miller et al. (2013), Mioshi et al. (2013a), Uflacker et al. (2016)

Lima-Silva et al. (2015), Mourik et al. (2004), Ng et al. (2012), Riedijk et al. (2006), Riedijk et al. (2008), Riedijk et al. (2009), Uflacker et al. (2015), Vugt et al. (2009), Wong and Wallhagen (2012)

Bock et al. (2016), Bristow et al. (2008)

Chio et al. (2010), Cosseddu et al. (2013), Cui et al. (2015)

Diehl-Schmid et al. (2013), Merrilees et al. (2010), Roche et al. (2015)

$\mathrm{Ng}$ et al. (2012)

Riedijk et al. (2006, 2008, 2009), de Vugt et al. (2006)

Ascher et al. (2010), Brodaty et al. (2014), Davis and Tremont (2007), Kaizik et al. (2017), Mekala et al. (2013), Merrilees et al. (2010), Mioshi et al. (2009), Mourik et al. (2004), Nicolaou et al. (2010), Ng et al. (2012), Riedijk et al. (2006), Riedijk et al. (2008), Riedijk et al. (2009), Rosness et al. (2008), Uflacker et al. (2015), de Vugt et al. (2006), Wong and Wallhagen (2012), Wong and Wallhagen (2014)

Armstrong et al. (2013), Boutoleau-Bretonniere et al. (2008), Brioschi Guevara et al. (2015), Bristow et al. (2008), Chow et al. (2011), Cosseddu et al. (2013), Diehl-Schmid et al. (2013), Hsieh et al. (2013), Hsieh et al. (2016), Knutson et al. (2008), Kumfor et al. (2016), Lima-Silva et al. (2015), Liu et al. (2017), Miller et al. (2013), Mioshi et al. (2013a), Uflacker et al. (2016)

Armstrong et al. (2013), Cosseddu et al. (2013), Diehl-Schmid et al. (2013), Kaiser and Panegyres (2006) Armstrong et al. (2013), Bristow et al. (2008), Chow et al. (2011), Hsieh et al. (2013), Hsieh et al. (2016), Kumfor et al. (2016), Liu et al. (2017), Miller et al. (2013), Mioshi et al. (2013a), Riedl et al. (2014)

Chow et al. (2011), Kumfor et al. (2014), Liu et al. (2017), Miller et al. (2013), Mioshi et al. (2013a), Riedl et al. (2014)

Armstrong et al. (2013), Chow et al. (2011), Knutson et al. (2008), Kaizik et al. (2017)

Chow et al. (2011), Davis and Tremont (2007), Kaizik et al. (2017)

6 Andrews et al. (2017), Bock et al. (2016), Chio et al. (2010), Cui et al. (2015), Hsieh et al. (2016), Lillo et al. (2012) 
Table 5. Continued

$\begin{array}{lcc} & \text { NUMBER OF } & \\ \text { CHARACTERISTIC } & \text { STUDIES } & \text { REFERENCES }\end{array}$

Country/region of origin (all studies)

USA/Canada

Europe

Australia

Caregiver characteristics in quantitative studies

Setting (patient living at home vs. institutionalized)

Relationship to patient

Gender
Armstrong et al. (2013), Ascher et al. (2010), Bock et al. (2016), Boxer et al. (2013), Brioschi Guevara et al. (2015), Caceres et al. (2016), Chemali et al. (2010), Chow et al. (2011), Davis and Tremont (2007), Denny et al. (2013), Dowling et al. (2014), Houseman et al. (2013), Knutson et al. (2008), Massimo et al. (2013, 2014), McCarter et al. (2016), Merrilees et al. (2007, 2013b), Morhardt (2011), O’Connell et al. (2014), Uflacker et al. (2015), Uflacker et al. (2016), Wong and Wallhagen (2012, 2014)

Boutoleau-Bretonniere et al. (2008), Chow et al. (2011), Chio et al. (2010), Cosseddu et al. (2013), Diehl et al. (2003, 2004), Diehl-Schmid et al. (2013), Ibach et al. (2004), Kindell et al. (2014), Mioshi et al. (2013b), Moretti et al. (2004), Mourik et al. (2004), Nunnemann et al. (2012), Oyebode et al. (2013), Riedijk et al. (2006) Riedijk et al. (2008), Riedijk et al. (2009), Riedl et al. (2014), Roche et al. (2015), Rosness et al. (2008), Vercelletto et al. (2011), de Vugt et al. (2006)

Andrews et al. (2017), Brodaty et al. (2014), Hsieh et al. (2013), Hsieh et al. (2016), Kaiser and Panegyres (2006), Kaizik et al. (2017), Kumfor et al. (2014), Kumfor et al. (2016), LoGiudice and Hassett (2005), Mekala et al. (2013), Miller et al. (2013), Mioshi et al. (2009), Mioshi et al. (2013a), Nicolaou et al. (2010), O’Connor et al. (2014, 2016)

Boutoleau-Bretonniere et al. (2008), Brodaty et al. (2014), Davis and Tremont (2007), Diehl-Schmid et al. (2013), Kaiser and Panegyres (2006), Mekala et al. (2013), Mioshi et al. (2009), Mourik et al. (2004), Nicolaou et al. (2010), Riedijk et al. (2006), Riedijk et al. (2008), Riedijk et al. (2009), Uflacker et al. (2016)

Armstrong et al. (2013), Ascher et al. (2010), Bristow et al. (2008), Brodaty et al. (2014), Chio et al. (2010), Cosseddu et al. (2013), Cui et al. (2015), Diehl-Schmid et al. (2013), Hsieh et al. (2013), Hsieh et al. (2016), Kaiser and Panegyres (2006), Kaizik et al. (2017), Kumfor et al. (2016), Lillo et al. (2012), Lima-Silva et al. (2015), Liu et al. (2017), Miller et al. (2013), Mioshi et al. (2013a), Mourik et al. (2004), Nicolaou et al. (2010), Riedijk et al. (2007), Riedijk et al. (2008), Riedijk et al. (2009), Riedl et al. (2014), Rosness et al. (2008), de Vugt et al. (2006), Wong and Wallhagen (2012)

Andrews et al. (2017), Ascher et al. (2010), Bristow et al. (2008), Brodaty et al. (2014), Chiò et al. (2010), Chow et al. (2011), Cosseddu et al. (2013), Davis and Tremont (2007), Denny et al. (2012), Diehl-Schmid et al. (2013), Hsieh et al. (2013, 2016), Kaiser and Panegyres (2006), Kaizik et al. (2017), Kumfor et al. (2016), Lillo et al. (2012), Lima-Silva et al. (2015), Liu et al. (2017), Mekala et al. (2013), Merrilees et al. (2010), Miller et al. (2013), Mioshi et al. (2009, 2013a), Mourik et al. (2004), Nicolaou et al. (2010), Riedijk et al. (2006, 2008, 2009), Riedl et al. (2014), Roche et al. (2015), de Vugt et al. (2006), Wong and Wallhagen (2012, 2014) 


\section{Setting}

Thirteen studies (references can be found in Table 5) gave accounts of the residency of the person with FTLD, the majority of them living in the community, i.e. living in their own home with assistance or with non-professional caregivers but not being admitted to care homes or hospitals.

Differences in the burden of caregivers of community-dwelling versus institutionalized patients have already been discussed in Nunnemann et al. (2012).

In the study of Rosness et al. (2008), 43\% of FTLD patients and $22 \%$ of $\mathrm{AD}$ patients were institutionalized in some way, but only $17 \%$ of FTLD long-term care residents lived in specialized care facilities. When also taking temporary admissions into short-term care into account, significantly more FTLD than early-onset $\mathrm{AD}$ patients had been admitted into care at some point during their disease. In a PPA cohort examined by Riedl et al. (2014), $40 \%$ of patients were institutionalized. However, $12 \%$ of patients had been denied admission to or had been discharged from a nursing home because staff members were not able to manage the symptoms exhibited by patients.

\section{Type of relationship}

Twenty-seven articles reported the type of caregiverpatient relationship and can be found in Table 5 . The studies of Mekala et al. (2013), Merrilees et al. (2010), Riedijk et al. (2006, 2008, 2009), Riedl et al. (2014), Rosness et al. (2008) and Wong and Wallhagen $(2012,2014)$ focused on family caregivers. Four studies (Ascher et al., 2010; Bristow et al., 2008; de Vugt et al., 2006; Kaiser and Panegyres, 2006) reported specifically on spousal caregivers. In these samples, spouses constitute $76.4 \%$ of all caregivers. The second-largest group of caregivers were children of any age (18.5\%), and other studies included siblings $(0.19 \%)$, friends $(0.19 \%)$, a parent $(0.04 \%)$, unspecified family members $(0.62 \%)$ and other caregivers not specified (3.9\%). In four cases, a paid caregiver was reported; however, these caregivers were excluded in other studies (Chio et al., 2010; Cui et al., 2015; Liu et al., 2017). Depression rates were significantly higher among spouses than among caregiving children (Cosseddu et al., 2013). The study of Kaizik et al. (2017) also compared the burden of spousal and child caregivers. Both groups reported similar levels of burden, stress and depression regardless of dementia severity. Child caregivers tended to report clinically significant anxiety levels and had significantly smaller social networks. The quality of the relationship was reported as suboptimal by both children and spouses. Moreover, children felt a significantly more controlling relationship towards them from their FTLD parent than spouses did. Younger caregiver age was associated with worse outcomes (Kaizik et al., 2017; Nicolaou et al., 2010; Wong and Wallhagen, 2012, 2014).

The only study to focus solely on children of FTLD patients was conducted by Denny et al. (2012) and will therefore be presented more in detail. A seven-person task force assessed the needs of children who were living with an FTLD patient when they were younger than 18 years of age. Therefore, Denny et al. conducted a literature search on child caregivers and anticipatory grief and an online search for support programs. For further insight, Denny et al. (2012) included anecdotal data from the Association for Frontotemporal Degeneration (AFTD) support groups and telephone services, and two postal and online surveys among affected children were conducted. It was found that existing support specified for children of FTLD parents is extremely limited. Some children provided hands-on help with personal care. Most participants found the most difficult aspect of the disease to be embarrassing behavior and the patient losing their role as a parent. Some children nevertheless stated that the care experience raised their responsibility and awareness of their own lives, but they were also concerned for their well parent. A portion of the respondents wished for interaction with other affected children and teenagers; however, the Internet was not found to be the most helpful resource compared to in-person support services.

\section{Gender}

Thirty-three studies reported caregiver gender (see Table 5 for references). Out of 3,090 total caregivers in these samples, the majority $(66.4 \%)$ were female.

Female caregivers were found to be more affected by problematic aspects of caregiving (Diehl-Schmid et al., 2013; Merrilees et al., 2010; Mourik et al., 2004; Nicolaou et al., 2010).

\section{Burden, challenges and unmet needs of caregivers of persons with FTLD}

Caregiver burden was found to be significantly associated with patients' behavioral changes (Armstrong et al., 2013; Boutoleau-Bretonniere et al., 2008; Cosseddu et al., 2013; Davis and Tremont, 2007; Diehl-Schmid et al., 2013; in SD and ALS-FTD: Hsieh et al., 2016; in bvFTD: Knutson et al., 2008; Liu et al., 2017; Ng et al., 2012; Uflacker et al., 2016). Frequently reported behavior changes were apathy (Armstrong et al., 2013; Boutoleau-Bretonniere et al., 2008; de Vugt et al., 2006; Lima-Silva et al., 2015; Riedijk et al., 2009; Uflacker et al., 2016; Wong and Wallhagen, 2012), disinhibition (Armstrong et al., 
2013; Boutoleau-Bretonniere et al., 2008; de Vugt et al., 2006; Lima-Silva et al., 2015; Liu et al., 2017; Uflacker et al., 2016), aberrant motor behavior (Boutoleau-Bretonniere et al., 2008; Liu et al., 2017; Riedijk et al., 2006) and changes in appetite and eating behavior (Boutoleau-Bretonniere et al., 2008; Wong and Wallhagen, 2012). Some patients exhibited criminal behavior as a result of their disease, which Wong and Wallhagen (2012) found in 9.8\% of their FTLD cohort. Thirty-five percent of FTLD patients in a study conducted by Rosness et al. (2016) had conflicts with local authorities or police, compared to $8 \%$ of $\mathrm{AD}$ patients. Such problems were also described for participants in the Chemali et al. (2010), Kumamoto et al. (2004) and Oyebode et al. (2013) case studies. FTLD patients performed significantly worse on an empathy (faux-pas) test than healthy peer group subjects, indicating that they experience difficulties in taking another person's viewpoint, when Brioschi Guevara et al. (2015) examined theory of mind (ToM) in FTLD patients. Impairments in ToM as well as atrophy in the left lateral premotor cortex, an area involved in ToM, were associated with higher caregiver burden.

All patient groups (bvFTD, SD, and AD) performed worse in emotion recognition than healthy controls when empathy loss was examined by Hsieh et al. (2013). In bvFTD, empathy loss was associated with a less-caring relationship between patient and caregiver. In SD patients, there was a trend of association between a lower empathy score and higher caregiver burden.

\section{Type of dementia}

Within the FTLD spectrum, caregiver burden was found to be significantly higher in bvFTD when compared to the language variants of FTLD and CBS (Cosseddu et al., 2013; Hsieh et al., 2016; Knutson et al., 2008; Liu et al., 2017; Mioshi et al., 2013a; Uflacker et al., 2016). Moreover, depression levels were higher in caregivers of bvFTD patients compared to PPA, AD and other dementias (Kaiser and Panegyres, 2006). Levels of burden and a controlling type of relationship in bvFTD and SD were found to be equal by Bristow et al. (2008) and Kumfor et al. (2014).

It is estimated that $8 \%$ of ALS patients meet criteria for bvFTD (Raaphorst et al., 2012). Seven studies (including the research overview by Houseman et al., 2013) reported on patients with overlapping ALS/FTD and their caregivers, a total of 429 patients. Of those, 32 had a confirmed diagnosis of ALS-FTD.

Behavioral disturbances similar to those seen in bvFTD predicted caregiver burden in all examined ALS cohorts (Andrews et al., 2017; Bock et al.,
2016; Chio et al., 2010; Cui et al., 2015; Hsieh et al., 2016; Lillo et al., 2012). Two studies also highlighted that those disturbances were more frequent in patients with a bulbar (vs. limb) onset of symptoms (Chio et al., 2010; Cui et al., 2015); however, this difference was not found by Lillo et al. (2012).

The papers of Uflacker et al. $(2015,2016)$ compared caregivers of bvFTD patients to those of patients with $\mathrm{AD}$ and sporadic Creutzfeld-Jakob disease (sCJD) or Prion disease. NPI distress and severity scores were comparably high between patients with FTLD and sCJD or Prion disease, respectively, in both papers and were both predictors of caregiver burden. Nineteen studies compared caregivers of FTLD patients to those providing care for $\mathrm{AD}$ patients, the most frequent type of dementia (Sacuiu, 2016). Eleven studies found the burden that caregivers of FTLD patients experience to be significantly higher than that of $\mathrm{AD}$ patients' caregivers (Boutoleau-Bretonniere et al., 2008; Brodaty et al., 2012; de Vugt et al., 2006; Hsieh et al., 2013; Kumfor et al., 2014; Liu et al., 2017; Miller et al., 2013; Mioshi et al., 2009, 2013a; Riedijk et al., 2006; Uflacker et al., 2016). Nevertheless, six studies could not find a difference in burden (Davis and Tremont, 2007; Kumfor et al., 2016; Lima-Silva et al., 2015; Merrilees et al., 2010; Nicolaou et al., 2010; Uflacker et al., 2015).

Moreover, three studies found caregiver depression to be higher in FTLD than in AD (Kaiser and Panegyres, 2006; Mioshi et al., 2009, 2013a). However, two studies (Kumfor et al., 2016; Nicolaou et al., 2010) could not find a difference.

Similarly, the study of Brodaty et al. (2014) found the burden to be highest in the FTLD group when also compared to that of caregivers of patients with vascular and mixed dementia.

\section{Dementia severity}

Other significant predictors of caregiver burden were dementia severity and a declining functional status, measured by impairments in activities of daily living (Davis and Tremont, 2007; Diehl-Schmid et al., 2013; Kaizik et al., 2017; in CBS: Knutson et al., 2008; Lima-Silva et al., 2015; Miller et al., 2013; (Mioshi et al., 2013a; Ng et al., 2012). Some papers also cited memory problems as significant contributors to caregiver burden (Chow et al., 2011; Kumfor et al., 2014; Miller et al., 2013); however, these problems tend to occur during later stages of the disease (Piguet and Hodges, 2013). When Kumfor et al. (2016) examined the memory retrieval of recent and remote events, no direct associations between bvFTD and SD memory performance and caregiver burden were found; 
however, there was a significant correlation between worse memory in SD patients and a more controlling relationship towards their caregivers. A worse memory of emotionally enhanced stories was associated with depression and stress in caregivers of PNFA patients (Kumfor et al., 2014). Atrophy in the anterior portions of the left inferior and medial temporal gyrus, involved in semantic memory, was found to be significantly correlated with caregiver burden in CBS patients (at $\mathrm{p}<0.01$ ) (Knutson et al., 2008). The relationship between atrophy of the right orbital gyrus and caregiver burden in the frontal variant of FTD (fvFTD) was found to be less significant and could be explained by a higher level of aggression associated with lesions in this area (at $\mathrm{p}<0.05$ ) (Knutson et al., 2008).

\section{Need for care}

The need for care and dependence of the patient was also a concern expressed by caregivers (Chow et al., 2011; Diehl-Schmid et al., 2013; Kaiser and Panegyres, 2006; Riedijk et al., 2009). Specific care challenges, such as hyperorality, sleep disorders and risky behavior, are described in Tables 3 and 4 .

\section{Financial aspects and employment}

As reported by Rosness et al. (2008), 61\% of FTLD patients versus $92 \%$ of $\mathrm{AD}$ patients were employed at the time of disease onset. Both women presented in the Chemali et al. (2010) and Kumamoto et al. (2004) case reports had lost their jobs as a result of disease symptoms. Not only is the patient's contribution to the household income lacking, but caregivers are also forced to reduce their paid working time. In the Bristow et al. (2008) study, $12 \%$ of caregivers were working full-time, $16 \%$ worked part-time, $68 \%$ were retired and $4 \%$ were unemployed. In the sample of Kaiser and Panegyres (2006), 25\% of spousal caregivers were employed. Of the concerns expressed by caregivers, "feeling stressed between caring for their spouse and trying to meet other responsibilities for their family or work" was the third-most frequently named. In the Mioshi et al. (2013a) interventional study, $56 \%$ of intervention caregivers and $34 \%$ of control group caregivers were employed. Among the participants of the Diehl et al. (2003) support group intervention, three out of eight were employed, one of them part-time. The difficulties of employment and caregiving at the same time are supported by reviews and research articles (Caceres et al., 2016; Diehl et al., 2004; LoGiudice and Hassett 2005; Morhardt 2011; Nunnemann et al., 2012; Shinagawa et al., 2015). Adapting to the role of a caregiver - not that of a spouse - which is inconsistent with the younger age, is described as burdensome in the studies of LoGiudice and Hassett (2005), Caceres et al. (2016) and Shinagawa et al. (2015). Financial issues can become a problem not only due to the loss of employment but also by the person with FTLD excessively spending money (LoGiudice and Hassett 2005; Morhardt, 2011) and because social benefits can be hard to obtain, as described for the US Medicare system by Morhardt (2011). Lower financial resources were found to partially predict caregiver strain in the study of Roche et al. (2015).

In a survey conducted among 30 members of an FTLD support group, in $35.7 \%$ of the sample, monthly care for the patient cost between $\$ 5,000$ and $\$ 9,999$, and in $21.5 \%$ of the sample, care expenses exceeded $\$ 10,000$ a month (Chemali et al., 2010).

\section{Consequences of burden}

Caregiving was shown $\mathrm{NN}$ ), using the Mental Component Summary (MCS) of the Short Form 36 (SF-36) health survey and the SF-12, respectively. The MCS comprises self-ratings concerning emotional role limitations, social functioning, mental health and general health perceptions (Riedijk et $a l ., 2006)$. In one study, caregiving was also shown to negatively influence the physical health of caregivers of bvFTD patients as represented by the Physical Component Summary (PCS) of the SF-36 (Cosseddu et al., 2013). Bristow et al. (2008) hypothesized that spousal caregivers of persons with FTLD suffer from chronic stress and distress and exhibit lower levels of IgA in saliva samples, indicating a suppressed immunity. However, no significant difference in the IgA levels was found between caregivers and healthy control subjects (also compare Nunnemann et al., 2012).

\section{Quality of relationship}

Another issue occurring during the process of caregiving is the deterioration of the relationship between the caregiver and patient (de Vugt et al., 2006; Kumfor et al., 2014; Mioshi et al., 2013a; Riedijk et al., 2008). The study of Ascher et al. (2010) found couples comprising an FTLD patient and a caregiver to be significantly less satisfied with their marriage and to be using more negative emotional language than healthy couples and couples comprising $\mathrm{AD}$ patients and their spouses. Participants of a telehealth support group comprising exclusively spouses of FTLD patients pointed out that relationships changed fundamentally, with a loss of affection and sexuality and a shift from the role as a spouse to that of a caregiver (O'Connell et al., 2014).

Patients with bvFTD had a less caring relationship to their caregivers, and SD patients showed a relationship with more control towards their 
caregivers (Hsieh et al., 2013; Mioshi et al., 2013b). Kumfor et al. (2016) found the level of control in the patient-caregiver relationship to be equal in SD and bvFTD.

However, no study assessed the quality of care provided to the person with dementia and a possible correlation to caregiver burden.

\section{Coping processes}

Four studies gave accounts of caregiver coping strategies and their effects. Active coping, acceptance, reassuring thoughts and problem- and emotionfocused coping were the most commonly used strategies (Riedijk et al., 2006; Roche et al., 2015; Wong and Wallhagen, 2014). Seeking distraction and dysfunctional coping were associated with increased caregiver burden, and the use of passive coping strategies - which were used the least - was correlated to worse mental health (Riedijk et al., 2006; Roche et al., 2015). Riedijk et al. (2008) determined that depressive reaction as a coping strategy increased significantly within a 24 -month time span. Women used emotion- and problem-focused coping significantly more than men, the first being associated with better relationship quality. The use of dysfunctional coping strategies was related to younger age and greater dissatisfaction with the relationship (Wong and Wallhagen, 2014).

\section{Support and Interventions for caregivers of persons with FTLD}

Nine studies reported on the needs and support provided for caregivers of patients with FTLD. Bristow et al. (2008) assessed the provision of emotional and practical support and the satisfaction with these forms of support. Satisfaction with the first person in the network - i.e., the partner cared for was significantly lower than in healthy control participants. The neurologist, information from the Internet and help from their own children were the most helpful resources, as stated in an online survey conducted by Chow et al. (2011). Other healthcare professionals and interventions, such as support groups, were cited less often.

Diehl-Schmid et al. (2013) asked caregivers to rate a variety of suggested support services and interventions for their perceived helpfulness. Caregivers most frequently found a greater provision of information and knowledge helpful in raising awareness not only for themselves but also for healthcare professionals. This lack of knowledge among healthcare professionals is supported by research overviews (Diehl et al., 2004; Morhardt, 2011; Nunnemann et al., 2012; Shinagawa et al., 2015) and was also described in Caceres et al. (2016). Since a portion of the Diehl-Schmid cohort reported a worsening of their financial situation, financial support was also rated as helpful, while pharmacological treatment for the patient and safety measures, e.g., monitoring devices, were not. Furthermore, caregivers wished for an all-inclusive information resource, e.g., trained staff that can provide counseling for legal, financial and social issues.

The study of Nicolaou et al. (2010) found caregivers of FTLD patients to have more needs than caregivers of $\mathrm{AD}$ patients and to require and receive more overall help, but receiving the same amount of help in formal care. Older caregivers had fewer overall needs and received less help but were more satisfied with the help received. Rosness et al. (2008) found that caregivers in FTLD, in comparison to those caring for an $\mathrm{AD}$ patient, were significantly less satisfied with the counseling, follow-up visits and information given to them.

Examining the care situation in patients with PPA, Riedl et al. (2014) determined that $58 \%$ of caregivers did not receive any kind of support. In $31 \%$, formal care help was provided, and $75 \%$ received financial support through the German care insurance system. Apart from support groups, which were utilized by $26 \%$ of caregivers, no other types of caregiver support were in use.

Diehl et al. (2004) and Morhardt (2011) sum up the problems that caregivers of FTLD patients frequently encounter. They mention difficulties in obtaining a correct diagnosis, which is supported by Nunnemann et al. (2012) and Shinagawa et al. (2015). A paucity of appropriate care facilities and interventions for the patient is described, not least due to the patients often being significantly younger than other dementia patients (Diehl et al., 2004; Caceres et al., 2016; LoGiudice and Hassett 2005; Morhardt, 2011; Nunnemann et al., 2012; Shinagawa et al., 2015). Uniquely, Ibach et al. (2004) assessed structural support offers for caregivers of people with FTLD in Germany in a survey conducted in 36 clinics for geriatric psychiatry, covering an area of $>20$ million inhabitants. Disease-specific counseling for caregivers was provided in $75 \%$ of clinics. Additionally, $61 \%$ offered support groups; however, it was not stated whether these support groups were aimed specifically at caregivers of FTLD patients. Eightynine percent of caregivers were referred to local Alzheimer's societies and $61 \%$ to other initiatives. Fewer referrals were correlated with a high proportion of dementia patients. However, $89 \%$ of clinics pointed out that there are fundamental deficits in the support provision for caregivers of FTLD patients. Clinics providing for a larger area had worse support offers, and more closed-ward beds were associated with less specific counseling.

Three studies (Boxer et al., 2013; Moretti et al., 2004; Vercelletto et al., 2011) assessed changes in 
caregiver burden in pharmacological studies for anti-dementia drugs in FTLD. Two studies reported on support groups (Diehl et al., 2003; O'Connell et al., 2014), two studies reported on interventional activities (Dowling et al., 2014; Mioshi et al., 2013b) for caregivers, and one study (O'Connor et al., 2016) examined the effect of an activity program for patients on caregiver burden.

Intervention procedures and results are summarized in Table 2.

Only the pharmacological study examining the effect of an acetylcholine receptor antagonist (Moretti et al., 2004) showed an improvement in caregiver stress and patient behavior; the other studies did not show significant effects.

Non-pharmacological caregiver interventions were generally reviewed as favorable and helpful, with an emphasis on the establishment of social contacts and mutual support from people in a similar situation.

The intervention aimed at the patient (O'Connor et al., 2016) was helpful in decreasing care time and easing the situation due to improved behavior and higher caregiver confidence.

\section{Discussion}

Our results revealed that during the past five years, the amount of literature on caregiver burden in FTLD has risen substantially. However, knowledge is still lacking data from specific fields of research, such as available support in different counties and the situation of child caregivers. Numerous studies comparing AD and FTLD have been conducted. Our results show that burden and depression are higher in caregivers of FTLD patients than those of $\mathrm{AD}$ patients. Reasons for this significant difference are likely to be found in the more burdensome set of behavioral symptoms developed by FTLD patients apathy, disinhibition, loss of empathy, aberrant motor behavior and changes in appetite and eating behavior - as opposed to the mainly cognitive decline, as exhibited with memory problems in AD (Sacuiu, 2016). Only two studies focusing on child caregivers of FTLD patients could be identified in the present review, even though the young age of onset of some patients with underage children is frequently stated as burdensome. Financial problems are another major challenge that caregivers of persons with FTLD must face. Not only is the patient no longer able to contribute to the family income, but the need for constant care and surveillance also requires the caregiver to reduce their working time or to pay for professional care. Another main concern for caregivers of FTLD patients is the lack of appropriate support and care services. Medical institutions and healthcare facilities are often not equipped to handle erratic behavioral disturbances, even leading to rejection of the patient. Not only relatives and friends but also a large number of healthcare professionals seem to be unaware of FTLD as a cause for behavioral change and cognitive deficits at a relatively young age. National associations for dementia should therefore intensify their actions in FTLD when educating both professionals and laypersons and highlight the existence of young-onset dementias and how they differ from well-known AD symptoms. Since data concerning the awareness of FTLD is lacking, a first step could be to assess awareness and knowledge about FTLD among family doctors, neurologists, psychiatrists and staff in dementia care facilities in order to provide advanced information tailored to existing levels of knowledge.

While some caregivers expressed hope in drug trials for pharmacological treatment in FTLD (Oyebode et al., 2013), previous studies found that therapies for patients with FTLD were less helpful in relieving the burden than strategies targeting caregivers directly (Diehl-Schmid et al., 2013). Two out of three pharmacological trials could not find a significant improvement in the caregiver's situation, nor were sufficient effects on the patient's symptoms shown.

Interventions aimed directly at the caregiver, however, led to a significant relief in burden. This review found that constructive coping techniques and mutual support, organized in caregiver support groups, were most helpful. It can therefore be concluded that the most efficacious measure when tackling caregiver burden are strategies for improving the caregiver's situation rather than trying to change the patient's behavior. Nevertheless, management strategies for erratic behaviors to reduce caregiver burden have been proposed. However, these strategies remain as reports of the clinical experiences of individual professionals. Randomized controlled trials are needed to assess the efficacy of these strategies.

Of the 69 papers considered in this review, 65 articles originated from Western industrialized countries. Only four articles included data from emerging countries, namely, China, Brazil and India. In a literature search investigating the epidemiology of FTLD, Onyike and Diehl-Schmid (2013) found that all studies reporting the prevalence or incidence of FTLD were conducted in Western industrialized countries, with preliminary studies only emerging from India and China. The study from Mekala et al. (2013) was the only paper to explicitly compare cross-cultural caregiver burden and found that the differing attitudes towards caregiving and ageing in societies of different cultural 
backgrounds as well as different healthcare structures influence the caregiving experience. More studies from emerging or developing countries would be helpful in addressing the caregiver burden specific to different cultural, social and economic backgrounds.

\section{Limitations and future research}

However, some limitations must be considered regarding the present review. Relevant articles could have been excluded if they were written in a language other than English or German, which may explain the publication bias for the country of origin. Especially studies from the Spanishspeaking world that could contribute findings from non-Western countries might have been missed by our search strategy. Studies that did not specifically provide information on persons with FTLD and their caregivers were also not included, so that more general aspects about caregiver burden in dementia might have been missed in this review. Moreover, the scope of the selected studies varies, and the quality of the studies was not assessed systematically to provide an overview of available research (Tricco et al., 2016). Thus, the quality of evidence reported here cannot be provided and could be assessed in systematic reviews focusing on specific aspects of burden in caregivers of persons with FTLD. Since nomenclature is not always used consistently and some studies fail to report exact numbers of diagnoses, comparisons might be distorted.

Future research should especially assess the situation of underage children in the context of symptoms unique to FTLD and possible interventions. The caregivers' financial and work situation, especially in comparison with the time before care became necessary, is another aspect that should be assessed in the future. Furthermore, the provision of care and support services specific to frontotemporal degeneration should be assessed in each country individually in order to recognize support gaps and lack of community support through health benefits.

Moreover, future research should assess whether the quality of care provided to the persons with dementia is affected by high levels of caregiver burden. This research question was already tackled for persons with dementia in general with a finding of good mental health being associated with a high quality of care (Morlett Paredes et al., 2017), but a special focus should be set on the distinct problems described above caregivers for persons with FTLD encounter.

\section{Conflict of interest}

None.

\section{Description of authors' roles}

T. Karnatz, M. Halek and J. R. Thyrian formulated the research question and designed the study. T. Karnatz carried out the study. T. Karnatz, J. Monsees, D. Wucherer, B. Michalowsky, I. Zwingmann, M. Halek, W. Hoffmann and J. R. Thyrian contributed to analyzing and interpreting the data and assisted in writing the article.

\section{Supplementary material}

To view supplementary material for this article, please visit https://doi.org/10.1017/S1041610219000176.

\section{References}

Andrews, S. C., Pavlis, A., Staios, M. and Fisher, F. (2017). Which behaviors? Identifying the most common and burdensome behavior changes in amyotrophic lateral sclerosis. Psychology, Health $\mathcal{E}$ Medicine, 22, 483-492. doi: 10.1080/13548506.2016.1164871.

Armstrong, N. et al. (2013). Caregiver burden in frontotemporal degeneration and corticobasal syndrome. Dementia and Geriatric Cognitive Disorders, 36, 310-318 doi: 10.1159/000351670.

Ascher, E. A., Sturm, V. E., Seider, B. H., Holley, S. R., Miller, B. L. and Levenson, R. W. (2010). Relationship satisfaction and emotional language in frontotemporal dementia and Alzheimer disease patients and spousal caregivers. Alzheimer Disease and Associated Disorders, 24, 49-55. doi: 10.1097/WAD.0b013e3181bd66a3.

Bock, M., Duong, Y-N., Kim, A., Allen, I., Murphy, J. and Lomen-Hoerth, C. (2016). Cognitive-behavioral changes in amyotrophic lateral sclerosis: screening prevalence and impact on patients and caregivers. Amyotrophic Lateral Sclerosis and Frontotemporal Degeneration, 17, 366-373. doi: 10.3109/21678421.2016 .1165257.

Boutoleau-Bretonniere, C. et al. (2008). Zarit burden inventory and activities of daily living in the behavioral variant of frontotemporal dementia. Dementia and Geriatric Cognitive Disorders, 25, 272-277. doi: 10.1159/000117394.

Boxer, A. L. et al. (2013). Memantine in patients with frontotemporal lobar degeneration: a multicentre, randomised, double-blind, placebo-controlled trial. The Lancet Neurology, 12, 149-156. doi: 10.1016/S14744422(12)70320-4.

Brioschi Guevara, A., Knutson, K. M., Wassermann, E. M., Pulaski, S., Grafman, J. and Krueger, F. (2015). Theory of mind impairment in patients with behavioral variant fronto-temporal dementia 
(bv-FTD) increases caregiver burden. Age and Ageing, 44, 891-895. doi: 10.1093/ageing/afv059.

Bristow, M. et al. (2008). Stress, distress and mucosal immunity in carers of a partner with fronto-temporal dementia. Aging E Mental Health, 12, 595-604. doi: 10 $.1080 / 13607860802343076$.

Brodaty, H. Seeher, K. and Gibson, L. (2012). Dementia time to death: a systematic literature review on survival time and years of life lost in people with dementia. International Psychogeriatrics, 24, 1034-1045. doi: 10.1017/ S1041610211002924.

Brodaty, H. et al. (2014). Prevalence and predictors of burden in caregivers of people with dementia. The American Fournal of Geriatric Psychiatry: Official fournal of the American Association for Geriatric Psychiatry, 22, 756-765. doi: 10.1016/j.jagp.2013.05.004.

Caceres, B. A., Frank, M. O., Jun, J., Martelly, M. T., Sadarangani, T. and Sales, P. C. de. (2016). Family caregivers of patients with frontotemporal dementia. An integrative review. International fournal of Nursing Studies, 55, 71-84. doi: 10.1016/j.ijnurstu.2015.10.016.

Chemali, Z., Withall, A. and Daffner, K. R. (2010). The plight of caring for young patients with frontotemporal dementia. American fournal of Alzheimer's Disease and Other Dementias, 25, 109-115. doi: 10.1177/1533317509352335.

Chio, A., et al. (2010). Neurobehavioral symptoms in ALS are negatively related to caregivers' burden and quality of life. European fournal of Neurology, 17, 1298-1303. doi: 10 $.1111 / \mathrm{j} .1468-1331.2010 .03016 . x$.

Chow, T. W., Pio, F. J. and Rockwood, K. (2011). An international needs assessment of caregivers for frontotemporal dementia. Canadian fournal of Neurological Sciences / Fournal Canadien des Sciences Neurologiques, 38, 753-757. doi: 10.1017/S0317167100054147.

Cosseddu, M. et al. (2013). The other face of the coin. The caregiver burden in frontotemporal lobar degeneration. International fournal of Geriatric Psychiatry, 28, 655-657. doi: $10.1002 /$ gps.3892.

Cui, B. et al. (2015). Behavioral symptoms in motor neuron disease and their negative impact on caregiver burden. Chinese Medical fournal, 128, 2295-2300. doi: 10.4103/ 0366-6999.163393.

Davis, J. D. and Tremont, G. (2007). Impact of frontal systems behavioral functioning in dementia on caregiver burden. The fournal of Neuropsychiatry and Clinical Neurosciences, 19, 43-49. doi: 10.1176/jnp.2007.19.1.43.

Denny, S. S. et al. (2012). Caring for children of parents with frontotemporal degeneration: a report of the AFTD Task Force on Families with Children. American fournal of Alzheimer's Disease and Other Dementias, 27, 568-578. doi: 10.1177/1533317512459791.

de Vugt, M. E. et al. (2006). Impact of behavioural problems on spousal caregivers. A comparison between Alzheimer's disease and frontotemporal dementia. Dementia and Geriatric Cognitive Disorders, 22, 35-41. doi: 10.1159/000093102.

Diehl, J., Forstl, H., Jansen, S. and Kurz, A. (2004). Frontotemporale Demenz. Besondere Probleme fur die Angehorigen. Zeitschrift fur Gerontologie und Geriatrie, 37, 301-306. doi: 10.1007/s00391-004-0202-9.

Diehl, J. et al. (2003). A support group for caregivers of patients with frontotemporal dementia. Dementia
(London, England), 2, 151-161 doi: 10.1177/

1471301203002002002 .

Diehl-Schmid, J. et al. (2013). Caregiver burden and needs in frontotemporal dementia. Fournal of Geriatric Psychiatry and Neurology, 26, 221-229. doi: 10.1177/ 0891988713498467.

Dowling, G. A., Merrilees, J., Mastick, J., Chang, V. Y., Hubbard, E. and Moskowitz, J. T. (2014). Life enhancing activities for family caregivers of people with frontotemporal dementia. Alzheimer Disease and Associated Disorders, 28, 175-181. doi: 10.1097/WAD .0b013e3182a6b905.

Gorno-Tempini, M. L. et al. (2011). Classification of primary progressive aphasia and its variants. Neurology, 76, 1006-1014. doi: 10.1212/WNL.0b013e31821103e6.

Houseman, G., Walsh, S., Brothers, A., Lyter, J., Simmons, Z. and Klapper, J. (2013). Frontotemporal degeneration in the patient with amyotrophic lateral sclerosis. Helping the caregiver cope. The fournal of Neuroscience Nursing: Fournal of the American Association of Neuroscience Nurses, 45, 96-100. doi: 10.1097/JNN $.0 \mathrm{~b} 013 \mathrm{e} 318282900 \mathrm{~b}$.

Hogan, D. B. et al. (2016). The prevalence and incidence of frontotemporal dementia: a systematic review. Canadian Fournal of Neurological Sciences / Fournal Canadien des Sciences Neurologiques, 43 Suppl 1, S96-S109. doi: 10.1017/ cjn.2016.25.

Hsieh, S. et al. (2013). When one loses empathy. Its effect on carers of patients with dementia. Fournal of Geriatric Psychiatry and Neurology, 26, 174-184. doi: 10.1177/ 0891988713495448.

Hsieh, S. et al. (2016). The evolution of caregiver burden in frontotemporal dementia with and without amyotrophic lateral sclerosis. Fournal of Alzheimer's Disease: $\mathcal{F A D}, 49$, 875-885. doi: 10.3233/JAD-150475.

Ibach, B. et al. (2004). Die Situation der Angehorigenberatung bei Patienten mit frontotemporaler lobarer Demenz in der Gerontopsychiatrie. Psychiatrische Praxis, 31 Suppl 1, S120-S122. doi: 10.1055/s-2004-828467.

Kaiser, S. and Panegyres, P. K. (2006). The psychosocial impact of young onset dementia on spouses. American Fournal of Alzheimer's Disease and Other Dementias, 21, 398-402. doi: 10.1177/1533317506293259.

Kaizik, C. et al. (2017). Factors underpinning caregiver burden in frontotemporal dementia differ in spouses and their children. Fournal of Alzheimer's Disease: $\mathcal{F A D}, 56$, 1109-1117. doi: 10.3233/JAD-160852.

Kindell, J., Sage, K., Wilkinson, R. and Keady, J. (2014). Living with semantic dementia: a case report of one family's experience. Qualitative Health Research, 24, 401-411. doi: 10.1177/1049732314521900.

Knutson, K. M. et al. (2008). Neural correlates of caregiver burden in cortical basal syndrome and frontotemporal dementia. Dementia and Geriatric Cognitive Disorders, 26, 467-474. doi: 10.1159/000167268.

Kumamoto, K., Arai, Y., Hashimoto, N., Ikeda, M., Mizuno, Y. and Washio, M. (2004). Problems family caregivers encounter in home care of patients with frontotemporal lobar degeneration. Psychogeriatrics, 4, 33-39. doi: 10.1111/j.1479-8301.2004.00064.x.

Kumfor, F., Hodges, J. R. and Piguet, O. (2014). Ecological assessment of emotional enhancement of 
memory in progressive nonfluent aphasia and Alzheimer's disease. Fournal of Alzheimer's Disease: $\mathcal{F A D}, 42,201-210$. doi: 10.3233/JAD-140351.

Kumfor, F. et al. (2016). Examining the relationship between autobiographical memory impairment and carer burden in dementia syndromes. Fournal of Alzheimer's Disease: FAD, 51, 237-248. doi: 10.3233/JAD-150740.

Lima-Silva, T. B. et al. (2015). Neuropsychiatric symptoms, caregiver burden and distress in behavioral-variant frontotemporal dementia and Alzheimer's disease. Dementia and Geriatric Cognitive Disorders, 40, 268-275. doi: 10.1159/000437351.

Lillo, P., Mioshi, E. and Hodges, J. R. (2012). Caregiver burden in amyotrophic lateral sclerosis is more dependent on patients' behavioral changes than physical disability: a comparative study. BMC Neurology, 12, 156. doi: 10.1186/ 1471-2377-12-156.

Liu, S. et al. (2017). The effects of behavioral and psychological symptoms on caregiver burden in frontotemporal dementia, Lewy body dementia, and Alzheimer's disease. Clinical experience in China. Aging $\mathcal{E}$ Mental Health, 21, 651-657. doi: 10.1080/13607863.2016 .1146871 .

LoGiudice, D. and Hassett, A. (2005). Uncommon dementia and the carer's perspective. International Psychogeriatrics, 17, S223. doi: 10.1017/ S1041610205002048.

Massimo, L. and Evans, L. K. (2014). Differentiating subtypes of apathy to improve person-centered care in frontotemporal degeneration. Fournal of Gerontological Nursing, 40, 58-65. doi: 10.3928/0098913420140827-01.

Massimo, L., Evans, L. K. and Benner, P. (2013). Caring for loved ones with frontotemporal degeneration: the lived experiences of spouses. Geriatric Nursing, 34, 302-306. doi: 10.1016/j.gerinurse.2013.05.001.

McCarter, S. J., St Louis, E. K. and Boeve, B. F. (2016). Sleep disturbances in frontotemporal dementia. Current Neurology and Neuroscience Reports, 16, 85. doi: 10.1007/ s11910-016-0680-3.

Mekala, S. et al. (2013). Cultural differences are reflected in variables associated with carer burden in FTD. A comparison study between India and Australia. Dementia E Neuropsychologia, 7, 104-109. doi: 10.1590/S198057642013DN70100016.

Merrilees, J. (2007). A model for management of behavioral symptoms in frontotemporal lobar degeneration. Alzheimer Disease and Associated Disorders, 21, S64-S69. DOI: 10 .1097/WAD.0b013e31815bf774.

Merrilees, J., Dowling, G. A., Hubbard, E., Mastick, J., Ketelle, R. and Miller, B. L. (2013). Characterization of apathy in persons with frontotemporal dementia and the impact on family caregivers. Alzheimer Disease $\mathcal{E}$ Associated Disorders, 27, 62-67. doi: 10.1097/WAD .0b013e3182471c54.

Merrilees, J. et al. (2010). Gender differences in the experience of dementia family caregivers. Alzheimer's $\mathcal{E}$ Dementia, 6, S336. doi: 10.1016/j.jalz.2010.05.1125.

Miller, L. A. et al. (2013). Identifying cognitive and demographic variables that contribute to carer burden in dementia. Dementia and Geriatric Cognitive Disorders, 36, 43-49. doi: 10.1159/000347146.
Mioshi, E. et al. (2009). Factors underlying caregiver stress in frontotemporal dementia and Alzheimer's disease. Dementia and Geriatric Cognitive Disorders, 27, 76-81. doi: 10.1159/000193626.

Mioshi, E. et al. (2013a). Improving burden and coping skills in frontotemporal dementia caregivers: a pilot study. Alzheimer Disease and Associated Disorders, 27, 84-86. doi: 10.1097/WAD.0b013e31824a7f5b.

Mioshi, E. et al. (2013b). The impact of dementia severity on caregiver burden in frontotemporal dementia and Alzheimer disease. Alzheimer Disease and Associated Disorders, 27, 68-73. doi: 10.1097/WAD .0b013e318247a0bc.

Moretti, R., Torre, P., Antonello, R. M., Cattaruzza, T., Cazzato, G. and Bava, A. (2004). Rivastigmine in frontotemporal dementia: an open-label study. Drugs $\mathcal{E}$ Aging, 21, 931-937.

Morhardt, D. (2011). Accessing community-based and long-term care services. Challenges facing persons with frontotemporal dementia and their families. Fournal of Molecular Neuroscience: MN, 45, 737-741. doi: 10.1007/ s12031-011-9612-5.

Morlett Paredes, A. et al. (2017). Structural equation model linking dementia cognitive functioning, caregiver mental health, burden, and quality of informal care in Argentina. Dementia (London, England), 16, 766-779. doi: 10.1177/1471301215617080.

Mourik, J. C. et al. (2004). Frontotemporal dementia. Behavioral symptoms and caregiver distress. Dementia and Geriatric Cognitive Disorders, 18, 299-306. doi: 10.1159/ 000080123.

Ng, A. et $\boldsymbol{a l}$. (2012). Severity of psychiatric symptoms correlates with activities of daily living and caregiver burden in frontotemporal dementia. Alzheimer's \& Dementia, 8, P568. doi: 10.1016/j.jalz.2012.05.1535.

Nicolaou, P. L. et al. (2010). Identifying needs, burden, and distress of carers of people with frontotemporal dementia compared to Alzheimer's disease. Dementia (London, England), 9, 215-235. doi: 10.1177/1471301209354024.

Nunnemann, S., Kurz, A., Leucht, S. and DiehlSchmid, J. (2012). Caregivers of patients with frontotemporal lobar degeneration. A review of burden, problems, needs, and interventions. International Psychogeriatrics, 24, 1368-1386. doi: 10.1017/ S104161021200035X.

O'Connell, M. E. et al. (2014). Development and evaluation of a telehealth videoconferenced support group for rural spouses of individuals diagnosed with atypical early-onset dementias. Dementia, 13, 382-395. doi: 10.1177/ 1471301212474143.

O'Connor, C. M., Ahmed, S. and Mioshi, E. (2014). Functional disability in primary progressive aphasia. Aphasiology, 28, 1131-1149. doi: 10.1080/02687038.2014 910588.

O'Connor, C. M., Clemson, L., Brodaty, H., Gitlin, L. N., Piguet, O. and Mioshi, E. (2016). Enhancing caregivers' understanding of dementia and tailoring activities in frontotemporal dementia: two case studies. Disability and Rehabilitation, 38, 704-714. doi: 10.3109/ 09638288.2015.1055375.

Onyike, C. U. and Diehl-Schmid, J. (2013). The epidemiology of frontotemporal dementia. International 
Review of Psychiatry (Abingdon, England), 25, 130-137. doi: 10.3109/09540261.2013.776523.

Oyebode, J. R., Bradley, P. and Allen, J. L. (2013). Relatives' experiences of frontal-variant frontotemporal dementia. Qualitative Health Research, 23, 156-166. doi: 10.1177/1049732312466294.

Peters, M. D. J. Godfrey, C. McInerney, P. Baldini Soares, C. Khalil, H. and Parker, D. (2017). Chapter 11: Scoping Reviews. In: E. Aromataris and Z. Munn (Eds.), foanna Briggs Institute Reviewer's Manual. Adelaide: The Joanna Briggs Institute. Available from https:// reviewersmanual.joannabriggs.org/.

Piguet, O. and Hodges, J. R. (2013). Behavioural-variant frontotemporal dementia. An update. Dementia $\mathcal{E}$ Neuropsychologia, 7, 10-18. doi: 10.1590/S198057642013DN70100003.

Raaphorst, J. et al. (2012). The ALS-FTD-Q: a new screening tool for behavioral disturbances in ALS. Neurology, 79, 1377-1383. doi: 10.1212/WNL $.0 \mathrm{~b} 013 \mathrm{e} 31826 \mathrm{c} 1 \mathrm{aa} 1$.

Rascovsky, K. et al. (2011). Sensitivity of revised diagnostic criteria for the behavioural variant of frontotemporal dementia. Brain: A fournal of Neurology, 134, 2456-2477. doi: 10.1093/brain/awr179.

Riedijk, S. et al. (2008). Frontotemporal dementia. Change of familial caregiver burden and partner relation in a Dutch cohort of 63 patients. Dementia and Geriatric Cognitive Disorders, 26, 398-406. doi: 10.1159/ 000164276 .

Riedijk, S. et al. (2009). Sense of competence in a Dutch sample of informal caregivers of frontotemporal dementia patients. Dementia and Geriatric Cognitive Disorders, 27, 337-343. doi: 10.1159/000207447.

Riedijk, S. R. et al. (2006). Caregiver burden, health-related quality of life and coping in dementia caregivers. A comparison of frontotemporal dementia and Alzheimer's disease. Dementia and Geriatric Cognitive Disorders, 22, 405-412. doi: 10.1159/000095750.

Roche, L., Croot, K., MacCann, C., Cramer, B. and Diehl-Schmid, J. (2015). The role of coping strategies in psychological outcomes for frontotemporal dementia caregivers. Fournal of Geriatric Psychiatry and Neurology, 28, 218-228. doi: 10.1177/0891988715588830.

Ried1, L. et al. (2014). Long-term follow-up in primary progressive aphasia. Clinical course and health care utilisation. Aphasiology, 28, 981-992. doi: 10.1080/ 02687038.2014.904497.
Rosness, T. A., Engedal, K., Bjertness, E. and Strand, B. H. (2016). Association between random measured glucose levels in middle and old age and risk of dementiarelated death. Fournal of the American Geriatrics Society, 64, 156-161. doi: 10.1111/jgs.13870.

Rosness, T. A., Haugen, P. K. and Engedal, K. (2008). Support to family carers of patients with frontotemporal dementia. Aging \& Mental Health, 12, 462-466. doi: 10. 1080/13607860802224334.

Sacuiu, S. F. (2016). Dementias. Handbook of Clinical Neurology, 138, 123-151. doi: 10.1016/B978-0-12-802973-2.00008-2.

Shinagawa, S. et al. (2015). Non-pharmacological management for patients with frontotemporal dementia: a systematic review. Fournal of Alzheimer's Disease, 45, 283-293. doi: 10.3233/JAD-142109.

Tricco, A. C. et al. (2016). A scoping review on the conduct and reporting of scoping reviews. BMC Medical Research Methodology, 16, 15. doi: 10.1186/s12874-016-0116-4.

Uflacker, A. et al. (2015). Caregiver burden in prion disease as compared to frontotemporal dementia and Alzheimer disease. The American fournal of Geriatric Psychiatry, 23, S141-S142. doi: 10.1016/j.jagp.2014.12.146.

Uflacker, A. et al. (2016). Caregiver burden in atypical dementias. Comparing frontotemporal dementia, Creutzfeldt-Jakob disease, and Alzheimer's disease. International Psychogeriatrics, 28, 269-273. doi: 10.1017/ S1041610215001647.

Vercelletto, M. et al. (2011). Memantine in behavioral variant frontotemporal dementia: negative results. Fournal of Alzheimer's Disease, 23, 749-759. doi: 10.3233/JAD-2010101632.

Vugt, M. E. de Riedijk, S. R., Aalten, P., Tibben, A., van Swieten, J. C. and Verhey, F. R. J. (2006). Impact of behavioral problems on spousal caregivers: a comparison between Alzheimer's disease and frontotemporal dementia. Dementia and Geriatric Cognitive Disorders, 22, 35-41. doi: 10.1159/000093102.

Wong, C. C. and Wallhagen, M. I. (2012). Frontotemporal dementia: the impact of patient behavioral symptoms on the physical and mental health of family caregivers. Dementia and Geriatric Cognitive Disorders Extra, 2, 516-528. doi: 10 $.1159 / 000345082$.

Wong, C. C. and Wallhagen, M. I. (2014). Family caregivers of individuals with frontotemporal dementia: examining the relationship between coping and caregiver physical and mental health. Fournal of Gerontological Nursing, 40, 30-40. doi: 10.3928/00989134-20130827-05. 